\title{
Formation and chemical composition of iron oxide precipitates from drainage waters in the western part of the Grantcharitsa deposit, Western Rhodopes
}

\section{Образуване и химичен състав на желязо-оксидни утайки в дренажни води в западната част на находище Грънчарица, Западни Родопи}

\author{
Mihail Tarassov $^{1}$, Milen Stavrev ${ }^{2}$, Eugenia Tarassova ${ }^{1}$, Elena Tacheva ${ }^{1}$, Aleksey Benderev ${ }^{2}$ \\ Михаил Тарасов", Милен Ставрев ${ }^{2}$ Евгения Тарасова $^{1}$, Елена Тачева ${ }^{1}$, Алексей Бендерев ${ }^{2}$ \\ ${ }^{1}$ Institute of Mineralogy and Crystallography, Bulgarian Academy of Sciences, Sofia, Bulgaria; E-mail: mptarassov@gmail.com \\ ${ }^{2}$ Geological Institute, Bulgarian Academy of Sciences, Sofia, Bulgaria
}

Keywords: iron oxide precipitates, drainage waters, tungsten deposit, Bulgaria.

\section{Introduction}

Ochreous iron oxide precipitates from drainage waters from abandoned mines or from oxidation zones of sulfide-containing deposits are an example of mineral forming processes carried out in situ and in real time. These processes are critical for the environment and are in focus of a large number of scientific articles and projects, since drainage waters are often acidic with an elevated content of dissolved metals, nonmetals, and metalloids recently recognized as a potential environmental concern (Akcil, Koldas, 2006; Nordstrom et al., 2015). The Grantcharitsa tungsten deposit (Western Rhodopes) has never been exploited, but the well-developed oxidation zone as well as the presence of prospecting galleries provide the conditions and possibilities for generating acid drainage waters. This scenario is partially implemented in the western part of the deposit, where drainage water from several closed adits is discharged into the Veziov Dol River and then enters the Bistritsa water conduit. In our previous study (Tarassov et al., 2019), we reported a sharp change in $\mathrm{pH}$ - from 2.4 (flood in April 2019) to 6.5 (low water level in September 2019) for drainage water from one of the galleries. There, the water discharge is accompanied by an intense precipitation of ochreous iron oxides. These precipitates and waters sampled at different times are the subject of the present study aimed at establishing the chemical and phase composition of the ochreous iron oxide materials and its relationship with the composition of the water.

\section{Material and methods}

Material. The sampling site is on the western slope of the Veziov Dol valley, close to a country road, where the drainage water springs, forming a reser- voir filled with iron oxide sludge. The place is partially overgrown with a grass (Fig. 1a), which means that neither drainage water nor iron oxides have a negative effect on plants. Samples of water and iron oxide sludge were taken 5 times in spring-summer (high-water) and autumn (low-water) seasons: April 2019 - sample 1, September 2019 - sample 2, May 2020 - sample 3, June 2020 - sample 4, and October 2020 - sample 5. It was confirmed that the $\mathrm{pH}$ value of water is a season-dependent parameter and is 2.4-4.7 and 5.7-6.5, in the spring-summer and autumn seasons, respectively. Water samples were evaporated in electric sand bath and then kept several hours in laboratory oven at $105^{\circ} \mathrm{C}$. The amount of the dry residue in each sample was determined by weighing. The obtained dry residues were placed into plastic containers suitable for long term storage. Samples of iron oxide sludge were dried to powder in a laboratory oven at $50{ }^{\circ} \mathrm{C}$. For analytical investigations in this work, pressed pellets were prepared from both dry residues and iron oxide powders.

Methods. The prepared samples were studied using scanning electron microscopy (SEM), electron-probe microanalysis (EPMA) and LA-ICP-MS analysis of trace elements. SEM and EPMA study were carried out on a ZEISS SEM EVO 25LS with an EDAX Trident system (Institute of Mineralogy and Crystallography (IMC), BAS) at acceleration voltage of $18 \mathrm{kV}$. EPMA was made at selected points (point analyses) and selected areas (area analyses) using an EDAX SDD Apollo 10 EDS detector and Genesis V. 6.2. software with ZAF correction method and hematite (for $\mathrm{Fe}$ ), diopside $(\mathrm{Mg})$, albite $(\mathrm{Na}, \mathrm{Al}, \mathrm{Si})$, sanidine $(\mathrm{K})$, apatite $(\mathrm{P})$, anhydrite $(\mathrm{S})$, tugtupite $(\mathrm{Cl})$ as reference standards. LA-ICP-MS analysis of 50 isotopes was performed on a PerkinElmer ELAN DRC-e ICP-MS with a 


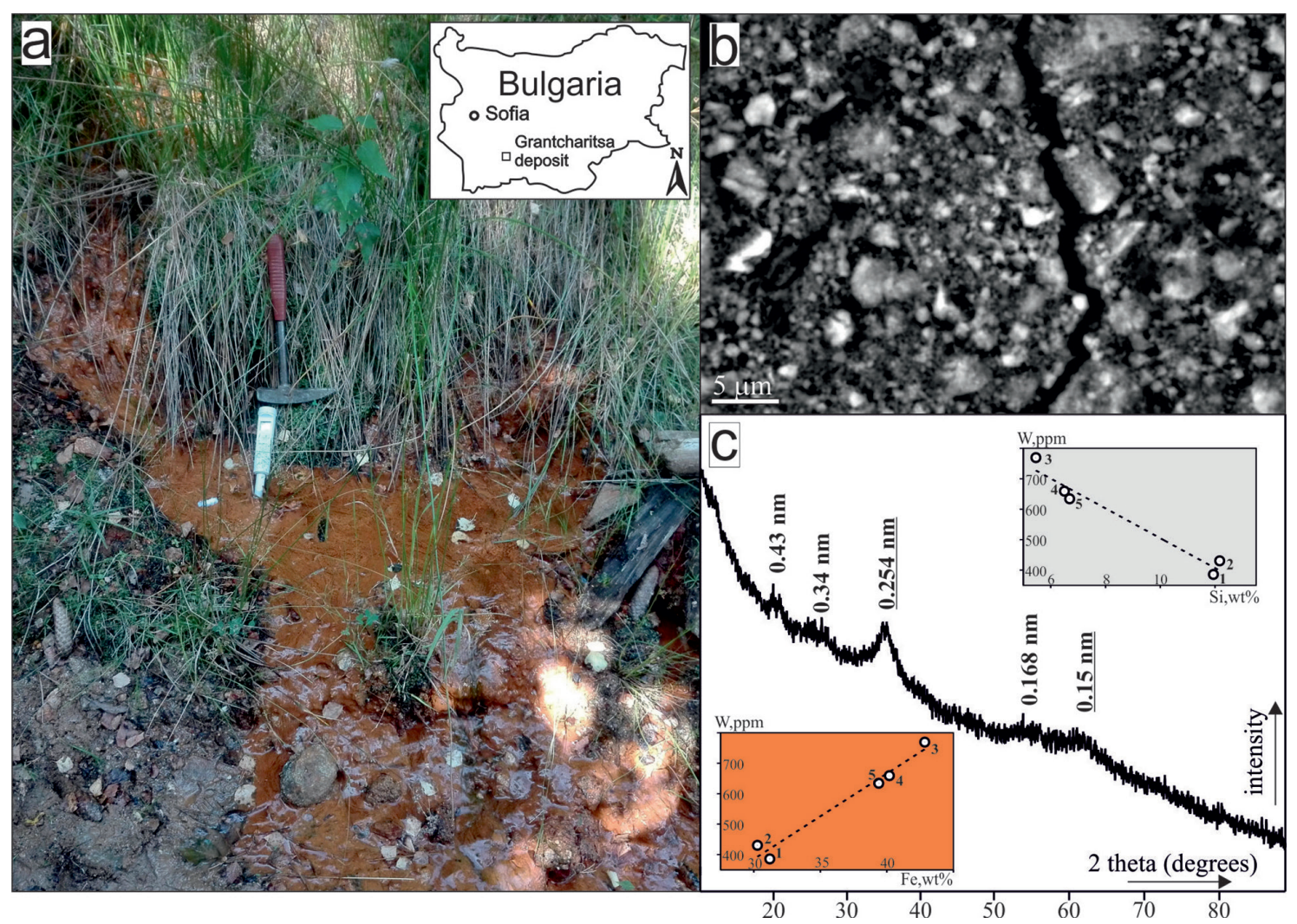

Fig. 1. $a$, site of sampling of drainage water and iron oxide precipitate (Veziov Dol valley, Grantcharitsa deposit); $b$, heterogeneity of iron oxide precipitates (October 2020): lighter areas indicate material richer in Fe and depleted in Si (SEM, backscattered electrons image); $c$, combined image of XRD pattern and graphs of dependences of the W content on the contents of Fe and $\mathrm{Si}$. Numbers from 1 to 5 correspond to samples taken on April 2019 (1), September 2019 (2), May 2020 (3), June 2020 (4), and October $2020(5)$

New Wave UP193FX LA system (Geological Institute (GI), BAS) at $5 \mathrm{~Hz}$ pulse rate, laser energy of $7.4 \mathrm{~J} / \mathrm{cm}^{2}$ and spot size of $100 \mu \mathrm{m}$. For better realibility, each sample was laser ablated in four selected areas. NIST 610 was applied as primary external standard for calibration of the analyzing system. SILLS software (Guillong et al., 2008) and the $\mathrm{SiO}_{2}$ content (as internal standard from EPMA) were used for data reduction and calculation of the chemical composition. The Fe-oxide materials were examined also with powder X-ray diffraction analysis on a PANanalytical EMPYREAN Diffractometer system (IMC-BAS), $\mathrm{Cu}$ anode, $45 \mathrm{~V}, 40 \mathrm{~mA}$, range 3-100 degrees 2Theta, step size 2Theta -0.0001 ).

\section{Results}

Elemental composition of iron oxide precipitates. SEM examination of the iron oxide pellets reveals that the all materials are inhomogeneous. The inhomogeneity is of two types: (1) presence of grains of rockforming mineral (acid plagioclase, potassium feldspar, quartz, biotite, muscovite and others), coming from the weathered host rocks (granodiorite); (2) inhomogeneity in the iron oxide precipitate itself. The first type inhomogeneity is found for samples taken on April and September 2019, while the second type is typical for all samples. The second type of inhomogeneity is illustrated in Figure 1b, where the light and dark areas (in backscattered electrons) correspond to materials with different chemical composition. EPMA examinations of sample 5 (October 2020) gives the following composition (in $\mathrm{wt} \%$ ) for the light areas: $\mathrm{Fe}_{2} \mathrm{O}_{3} 81.43, \mathrm{SiO}_{2}$ 11.77, $\mathrm{SO}_{3} 3.27, \mathrm{Al}_{2} \mathrm{O}_{3} 2.35, \mathrm{P}_{2} \mathrm{O}_{5}$ $0.52, \mathrm{MgO} 0.24, \mathrm{CaO} 0.11, \mathrm{Cl} 0.05$, total 99.73, and for the dark areas: $\mathrm{Fe}_{2} \mathrm{O}_{3} 65.14, \mathrm{SiO}_{2}$ 15.82, $\mathrm{SO}_{3}$ 1.26, $\mathrm{Al}_{2} \mathrm{O}_{3}$ 5.63, $\mathrm{P}_{2} \mathrm{O}_{5}$ 0.57, $\mathrm{MgO} 0.29, \mathrm{CaO} 0.26$, total 89.13. The obtained result means that the considered sample consists of two main constituents: the first one is a dense material strongly dominated by $\mathrm{Fe}_{2} \mathrm{O}_{3}$ in the composition, while the second and predominant material is less dense as indicated by the lower sum for analysis ( $>89 \mathrm{wt} \%)$, with the lower content of $\mathrm{Fe}_{2} \mathrm{O}_{3}$ and the higher contents of $\mathrm{SiO}_{2}$ and $\mathrm{Al}_{2} \mathrm{O}_{3}$. It is noteworthy, that the compositions of the similar areas in the other samples, regardless of the date of their collection, are very similar. The series of samples collected in 2020 (Nos 3, 4 and 5) shows an increasing trend in the proportion of less dense material. This trend correlates with the general tendency 
of increasing the $\mathrm{pH}$ of drainage water from spring to autumn. SEM study shows that both materials consist of nanometric particles with size of 100-200 nm, coalesced into 400-600 $\mathrm{nm}$ aggregates and then larger aggregates with a size of $1-3 \mu \mathrm{m}$.

The performed EPMA examination of the samples did not reveal the presence of $\mathrm{W}$ in a concentration above the detection limit of the method $(\sim 0.1 \mathrm{wt} \%)$. The applied LA-ICP-MS analysis of the samples shows W concentrations in the range 390-770 ppm. These concentrations cannot be attributed to any of the above materials since the diameter of the ablated area $(100 \mu \mathrm{m})$ is essentially larger than their particles and aggregates. The resulting content of $\mathrm{W}$ in iron oxide precipitates does not correlate with either the $\mathrm{pH}$ of the drainage waters or the sampling season. The $\mathrm{W}$ content has a positive correlation with the total (average) iron content and a negative correlation with the total (average) silicon content (Fig. 1c, see inserts). The average compositions of the samples were obtained using EPMA in scan mode (area analysis).

Phase composition of iron oxide precipitates. Representative powder X-ray diffraction pattern of the studied iron oxide precipitates shown in Figure $1 \mathrm{c}$ defines them as low crystalline materials. The pattern contains several weak and hardly resolved broad peaks centered at (in nm): $0.43,0.34,0.254$ (most intense peak), 0.168 and 0.15 (second more intense peak), which makes it difficult to unambiguously identify the phase/phases. With the exception of the peak at $0.43 \mathrm{~nm}$, all other peaks are in good agreement with the diffraction pattern of schwertmannite (oxyhydroxysulphate of iron) (Bigham et al., 1994). The pattern can also be attributed to 6-lines ferrihydrite (Drits et al., 1993). Most likely, the diffraction patterns of the studied materials correspond to a mixture of ferrihydrite and schwertmannite partially replaced by goethite (peak at $0.43 \mathrm{~nm}$ ). Similar mixtures of iron minerals in mine waters have already been described in the literature for other deposits (Bigham et al., 1996).

Composition of dry residues of drainage water. The chemical composition of the dry residues as determined with EPMA is dominated by $\mathrm{SiO}_{2} 27-48 \mathrm{wt} \%$ and $\mathrm{SO}_{3}-17-34 \mathrm{wt} \%$. The ratio between the two components is strongly sensitive to water $\mathrm{pH}$ : the highest concentrations of $\mathrm{SO}_{3}$ are found for waters collected during the spring-summer season when the $\mathrm{pH}$ value is low. For $\mathrm{SiO}_{2}$ the trend is reversed. The other components in the dry residue are (in wt $\%$ ): $\mathrm{CaO} 7-10, \mathrm{Na}_{2} \mathrm{O} 7-10, \mathrm{MgO} \sim 3, \mathrm{~K}_{2} \mathrm{O} \sim 1$. It is noteworthy that the presence of iron has not been detected by EPMA. LA-ICP-MS analysis reveals low concentrations of $\mathrm{Fe}-20-30 \mu \mathrm{g} / 1$ (recalculated per 1 liter of water) and without any correlations with $\mathrm{pH}$. The established concentration of $\mathrm{W}$ in the water is $0.1-1.3 \mu \mathrm{g} / 1$, with the lowest content being during the spring-summer season. The total mineralization of the water calculated from the weighed dry residues is $110-120 \mathrm{mg} / \mathrm{l}$.

\section{Conclusions}

- The studied drainage water entering into Veziov Dol River is low-mineralized with a pronounced seasonally dependent $\mathrm{pH}$ parameter. The water acquires the features typical for acid mine drainage only during the season of high waters, while at other time it is gradually neutralized.

- Low crystalline (ferrihydrite+schwetmannite) precipitates found in the place of water discharge have the following features: 1) they are inhomogeneous with a variable content of $\mathrm{Si}$ and $\mathrm{Fe}$; (2) the W content in them correlates with the Fe content; (3) there is no clear dependence of their chemical composition on $\mathrm{pH}$ and chemical composition of water.

- The relationship between the two components of the studied drainage system - (1) water and (2) iron oxide precipitates is not entirely obvious and requires additional investigation. It is necessary to clarify the mechanism and conditions for the formations of parts of the sediments dominated by $\mathrm{Fe}_{2} \mathrm{O}_{3}$ and $\mathrm{Fe}_{2} \mathrm{O}_{3}+\mathrm{SiO}_{2}$.

Acknowledgements: The study was supported by the National Science Fund of Bulgaria (Contract № KP-06-OPR 03/5, 2018). The authors acknowledge the technical support from the project PERIMED BG05M2OP001-1.002-0005/29.03.2018 (2018-2023).

\section{References}

Akcil, A., S. Koldas. 2006. Acid Mine Drainage (AMD): causes, treatment and case studies. - J. Cleaner Production, 14, 1139-1145.

Bigham, J. M., L. Carlson, E. Murad. 1994. Schwertmannite, a new iron oxyhydroxysulphate from Pyhasalmi, Finland, and other localities. - Mineral. Mag., 58, 641-648.

Bigham, J. M., U. Schwertmann, S. J. Traina, R. L. Winland, M. Wolff. 1996. Schwertmannite and the chemical modeling of iron in acid sulfate waters. - Geochim. Cosmochim. Acta, 60, 12, 2111-2121.

Drits, V. A., B. A. Sakharov, A. L. Salyn, A. Manceau. 1993. Structural model for ferrihydrite. - Clay Miner., 28, 185-207.

Guillong, M., D. Meier, M. Allan, C. Heinrich, B. Yardley. 2008. Appendix A6: SILLS: A MATLAB-based program for the reduction of laser ablation ICP-MS data of homogeneous materials and inclusions. - In: Sylvester, P. (Ed.), Laser Ablation ICP-MS in the Earth Sciences: Current Practices and Outstanding Issues. Vancouver, B. C., Mineralogical Association of Canada, Short Course 40, 328-333.

Nordstrom, D. K., D. W. Blowes, C. J. Ptacek. 2015. Hydrogeochemistry and microbiology of mine drainage: An update. - Applied Geochem., 57, 3-16.

Tarassov, M., A. Benderev, M. Trayanova, E. Tarassova. 2019. Preliminary data on the content of $\mathrm{W}$, As and $\mathrm{U}$ in the waters in the area of the Grantcharitza deposit, Western Rhodopes. - Rev. Bulg. Geol. Soc., 80, 3, 239-241. 